\title{
How can personal development lead to increased engagement? The roles of meaningfulness and perceived line manager relations
}

There is an increasing need to understand the psychological processes that link personal development with employee engagement, particularly the boundary conditions at which these occur. The current study sought to meet this need by testing whether perceived opportunities for development are positively associated with job engagement indirectly through the experience of meaningfulness, and whether this indirect relationship is conditional on the level of perceived line manager relations. Questionnaire data was collected from 152 UK workers from a range of occupations and organizations. The results found support for all the hypotheses. In particular, the positive effects of perceived opportunities for development on job engagement (measured one month later) via meaningfulness was only significant for those who perceived that they had a good relationship with their line manager. Thus, there is a need for line managers to develop high quality relationships with their direct reports in order for development practices to translate into positive psychological outcomes. Engagement theory could be advanced by further understanding broaden-and-build and social exchange processes.

Keywords: personal development; line management; meaningfulness; engagement; moderated mediation 


\section{Introduction}

Providing opportunities for personal development is a crucial practice within a human resource management (HRM) system because such opportunities develop human capital resources within the organization, which enable sustained competitive advantage (Lee \& Bruvold, 2003). Moreover, opportunities for development are important for facilitating employee engagement (Bakker \& Bal, 2010; Sarti, 2014; Shuck, Twyford, Reio, \& Shuck, 2014). Engagement is defined as the authentic, simultaneous expression of one's emotional, cognitive, and physical dimensions of the self whilst performing one's job role (Kahn, 1990). In doing so, personal development connects the individual with their work context because "they provide pathways for employee growth and fulfillment" (Crawford, Rich, Buckman, \& Bergeron, 2014, p.61). Over recent years initiatives to improve employee engagement have become widespread because of their potential to leverage organizational success through harnessing the motivation and spirit of its employees (Saks \& Gruman, 2014). As HRM practitioners are often responsible for leading organizational change initiatives that seek to improve employee engagement through human resource (HR) practices (Arrowsmith \& Parker, 2013; Reissner \& Pagan, 2013), and given that a recent evidence synthesis shows that employee perceptions of development are associated with engagement (Bailey, Madden, Alfes, \& Fletcher, 2015), it may be particularly useful for HRM researchers to examine the psychological processes that underpin the relationship between personal development and engagement in more depth. Currently, there is a lack of understanding of how personal development leads to engagement, and in what circumstances this process occurs. This is important to address because it provides practical recommendations on how development practices can be best designed and implemented to facilitate engagement, as well as theoretical insight into the psychological foundations of engagement and how these can be influenced by contextual factors. 
This paper aims to develop such an insight by examining whether meaningfulness, a key precondition of engagement (Kahn, 1990), is a critical psychological process that explains how perceptions of personal development lead to engagement; and whether this process is contingent upon one's perceived relationship with one's line manager. Although a few studies have shown that perceived development is directly linked to engagement (e.g., Bakker \& Bal, 2010; Sarti, 2014; Shuck et al., 2014), a scarce number have examined potential mediating processes that underpin this relationship. For example, Bal, Kooji, and de Jong (2013) examined how the availability of developmental HRM (including job development/enrichment/rotation, internal promotion, and lateral job movement), at the unit level, was related to engagement, at the individual level, via psychological contract perceptions, at the individual level. The current study complements and extends Bal et al.'s (2013) study by examining employee perceptions of development practices, rather than just whether they are available to them, and by focusing specifically on opportunities for personal development, rather than on a range of job design/development factors. Focusing on perceptions of HR practices are important as employees vary in how they react to implemented practices, and differ in the attributions they make about why management enact these practices, which influences the way each individual behaves and acts (Nishii, Lepak, \& Schneider, 2008). Moreover, the current study will probe the boundary conditions of the mediating process that links personal development and engagement by testing whether the relationship with the line manager has a moderating influence. Given that line managers enact development practices on a day-to-day basis, such as career management (Crawshaw \& Game, 2015), the relationship between the employee and their line manager may strengthen or weaken the positive effects of opportunities for development depending on the extent to which this relationship is perceived as supportive. 
This paper will contribute to the engagement literature in the following ways. First, it will strengthen the evidence base that perceived opportunities for development are important for facilitating engagement. Although there is growing evidence to show that job resources, as a collection of physical, social and organizational aspects of a job, promotes high levels of engagement (Bailey et al., 2015), there are a lack of studies that specifically examine the effects of development practices and engagement (Shuck et al., 2014). Therefore, there is a need to strengthen this particular body of evidence as the effects of personal development on engagement has, to date, been subject to only a handful of studies. Second, the study will provide further insight into the role of meaningfulness as a key psychological condition of engagement. Despite contemporary theorizing on engagement positioning meaningfulness as a critical intermediary process that connects perceptions of the wider work context with the experience of engagement (Kahn \& Heaphy, 2014), there remains little specific understanding or evidence about how HR practices, such as personal development, may facilitate engagement via meaningfulness. This has been highlighted as an important gap to address as such studies will reveal the psychological processes that underpin HR practices and may help to integrate different theoretical perspectives to advance our understanding of how HRM can facilitate engagement (e.g., Fletcher, 2016; Shuck \& Rose, 2013). Third, by examining the role of the line manager as a boundary condition for the effects of personal development this study will shed light on the contextual factors that impact on how engagement is experienced, and will provide a more nuanced understanding of engagement's theoretical foundations, particularly that of social exchange (Blau 1964). Qualitative studies have highlighted how management behave and relate to employees will influence the way in which the wider organizational context shapes 
the experience of engagement (e.g., Arrowsmith \& Parker, 2013; Reissner \& Pagan, 2013). Therefore, the current study will complement these studies by providing a quantitative examination of the role of the line manager in shaping how development practices impact on engagement.

\section{Theoretical background and hypotheses}

\section{The association between perceived opportunities for development and engagement}

Having opportunities to undertake personal development activities, such as leading a new project or undertaking a qualification/formal learning experience, signifies that the organization values and cares about them as individuals, and as important for the success of the organization (Lee \& Bruvold, 2003). Thus, personal development can be seen as a way in which the employer and employee can participate in social exchanges because the employer is giving the employee opportunities to acquire and develop valuable resources in the form of skills, abilities and knowledge (Koster, de Grip, \& Fouarge, 2011). The theory of social exchange (Blau, 1964) posits that an employee and their employer participate in an ongoing exchange of resources that occurs within a framework of rules and norms of reciprocity, such that when an employee receives resources from the other party they will feel obliged to repay in kind. Social exchange involves not only economic (i.e. tangible) resources, such as pay and incentives, but also socio-emotional (i.e. intangible) resources, such as social support and recognition. If the employee receives these resources from their employer, via practices such as personal development, they may feel obliged to repay their employer by engaging more with their work (Shuck et al., 2014). This is because engagement is assumed to be within the individual's power to some degree, i.e. the degree to which the individual engages with their work is a choice that the individual themselves makes (Kahn, 1990; Kahn, 2010).

Moreover, personal development can be seen as an important job resource; such resources connote physical, social, or organizational features related to the job that are 
functional in achieving goals and personal growth as well as in reducing job demands and their associated costs (Crawford et al., 2014). According to job demands-resources (J D-R) theory (Bakker \& Demerouti, 2008), job resources, such as opportunities for development, facilitate motivational psychological states, particularly that of engagement, as they help to fulfil both extrinsic (e.g., goal accomplishment) and intrinsic (e.g., competency) motivational needs. Therefore, employees who perceive that they have many opportunities to develop their personal skill/abilities, as well as careers, within their organization are more likely to feel engaged with their work roles than those that do not hold those perceptions. Indeed there is some evidence to show that perceptions regarding opportunities for development are positively associated with engagement. Bailey et al. (2015) systematically reviewed the engagement literature to find that 26 empirical studies out of 172 that met the quality criteria for inclusion (from 5771 items) examined the association between a range of job resources and engagement, yet only one examined the specific relationship between opportunities for development and engagement, with this finding a positive association. Additionally, Shuck et al (2014) found, within a sample of 207 employees in the health care industry, that perceived support for participation in human resource development practices was positively and similarly related to each dimension of engagement (i.e., emotional, cognitive, behavioural).

\section{The association between meaningfulness and engagement}

A core feature of contemporary engagement theory is the positioning of meaningfulness as a critical psychological condition of engagement (Kahn, 1990). Meaningfulness connotes “feeling that one is receiving a return on investments of one's self in a currency of physical, cognitive, or emotional energy" (Kahn, 1990, p.703-4). In other words "people need to feel as if they matter, that their contributions have meaning" (Kahn, 2010, p.24). Although the body 
of literature on meaningfulness is fragmented, there is consensus that meaningfulness refers to perceiving one's work as particularly significant and valuable (Rosso, Dekas, \& Wrzesniewski, 2010). These perceptions are argued to be necessary for the experience of engagement as they incentivize the investment of one's energies into one's work role (Kahn, 1990), and deepen the purpose and personal fulfilment of work and the work context (Kahn \& Heaphy, 2014). This corresponds with conservation of resource (COR) theory (Hobfoll, 1989) which argues that individuals invest their own psychological resources in this way in order to protect and enhance their sense of wellbeing. Investing resources helps them to selfregulate, manage their social relationships, and fit into the wider organizational context (Hobfoll, 2011). Thus, investment in one's work role through the experience of meaningfulness leads to higher engagement as it improves psychological functioning, which then allows for further investment, i.e. a gain spiral effect. Indeed, there is empirical evidence supporting this claim, for example Xanthopoulou, Bakker, Demerouti, and Schaufeli (2009a) found, within a sample of 163 employees, reciprocal relationships between personal resources and engagement across an 18-month period. Accordingly, individuals who experience meaningfulness will be motivated to invest more of themselves into their work role (i.e., engagement) because they feel that in doing so they will be better able to protect and enhance their well-being. Indeed, there is growing evidence demonstrating that meaningfulness increases levels of engagement (e.g., Chen, Zhang, \& Vogel, 2011; May, Gilson, \& Harter, 2004; Soane et al., 2013).

\section{Meaningfulness as a mediating process that connects personal development with the experience of engagement}

Meaningfulness is not just a key antecedent of engagement; it is also proposed to be a core psychological process that connects perceptions of the wider work environment with 
engagement (Kahn, 1990; Saks \& Gruman, 2014). This is because meaningfulness acts as a motivational pathway that transforms the value and purpose derived from the work context into a positive and fulfilling personalized experience (Shuck \& Rose, 2013). Indeed, evidence has shown that meaningfulness links work contextual perceptions of job enrichment and work role fit with increased engagement (May et al., 2004); however no studies have explored whether this in case for the relationship between personal development and engagement. Having opportunities to develop one's skills, abilities and career aspirations will enable personal growth and fulfilment, and will prepare one for changes to one's job, e.g. increased responsibility, challenge or promotion (Crawford et al., 2014). This increases the personal value and significance of one's work, i.e. meaningfulness, which in turn fosters engagement (Kahn, 1990; Soane et al., 2013), and as such reflects Fredrickson's (2001) broaden-and-build theory and the theory of purposeful work behavior (Barrick, Mount, \& Li, 2013). More specifically, perceiving that one has ample opportunities to develop personal skills/abilities and career aspirations enhances one's sense of meaningfulness as such perceptions signify to the individual that their unique skills, responsibilities, and work activities hold value and worth (Kahn, 1990; Lee \& Bruvold, 2003). As reflected in Fredrickson's (2001) broadenand-build theory, this sense of meaningfulness then broadens affective and cognitive processes through promoting a wider interest in the work context, for example work goals and expected performance behaviour (Barrick et al., 2013; Soane et al., 2013). In consequence, engagement is heightened because, as an affective-cognitive psychological state, it is activated when meaningfulness is experienced (Kahn, 1990). Thus, the relationship between perceived opportunities for development and engagement is likely to be mediated by meaningfulness.

Hypothesis 1: Meaningfulness mediates the relationship between perceived opportunities for development and engagement. 


\section{The moderating role of perceived line manager relations}

There is a need to explore and test interactions between different antecedents of engagement because there is an untested and uncritical assumption that all resources have the same linear and independent effects (Crawford et al., 2014). Given that there is emerging evidence that resources interact to influence engagement, it is important to further examine potential moderation effects to advance engagement theory. For example, Zhu, Avolio and Walumbwa (2009) found that follower characteristics strengthened the positive relationship between transformational leadership and follower work engagement; and Mendes and Stander (2011) revealed that empowering leadership interacted with role clarity to influence engagement.

The current study aims to examine the potential moderating role that line managers have on the relationship between perceived opportunities for development and meaningfulness. Line managers can create meaning and purpose for employees by enacting behaviors that raise morality and commitment, providing positive cues about the importance and wider utility of their work, and inspiring creativity and action (Rosso et al., 2010). According to social exchange theory (Blau, 1964) employees and line managers can develop a high quality relationship because they participate and invest, over time, in the mutual reciprocation of socio-emotional resources, such as support and trust. Although this theory has been used to explain the mediation processes that link perceptions of development with engagement (e.g. Shuck et al., 2014), a growing number of scholars argue that social exchange mechanisms may moderate or accentuate the psychological processes that translate HR practices into positive employee states, attitudes and behavior (e.g., Alfes, Shantz, Truss, \& Soane, 2013; Kuvaas \& Dysvik, 2010; Kuvaas, Buch, \& Dysvik, 2012). This is because line managers are often responsible for the day-to-day implementation of HR practices (Wright \& Nishii, 2007) and play a key role in the career management of their direct reports (Crawshaw \& Game, 2015), and so they act as deliverers and implementers of personal 
development practices and as agents of the organization (Kuvaas \& Dyskvik, 2010). Supportive managers who display leadership behaviours are important for ensuring the delivery and implementation of HRM to frontline staff results in favourable employee outcomes (Purcell \& Hutchinson, 2007). As line managers are implementers of HR practices, employees will interact with them regularly and perceive them, in part, as an agent of the organization, and therefore the employee will participate in an exchange of socio-emotional resources with their line manager and over time this develops into a long-term social exchange relationship (Wayne, Shore, \& Liden, 1997).

Social exchange relationships strengthen the experience of, and provide further legitimation for, personal development and so social exchange theory may explain the conditions under which personal development results in positive effects (Kuvaas \& Dyskvik, 2010). When one has a positive relationship with one's manager, felt obligations towards the manager and the expectation of mutual reciprocity will be stronger than when one has a weak or negative relationship with one's manager (Wayne et al., 1997). A high level of perceived opportunities for development coupled with a positive perception of the relationship with one's manager, will result in a particularly strong obligation to reciprocate by way of positive attitudes and behaviors towards both the manager and the organization (Kuvaas \& Dyskvik, 2010). Given that meaningfulness is facilitated by both the manager, such as through leadership behaviors, goal setting, and communication, and by the organization, such as through its mission, values, and practices (Rosso et al., 2010), perceived opportunities for development will interact with the perceptions regarding the relationship with one's line manager to influence meaningfulness. Thus, the positive effects of personal development on meaningfulness will be strengthened when such felt obligations and reciprocity are particularly salient because the individual will also be motivated to 
sustain the social exchange relationship between themselves and their manager. In order to maintain this relationship, the individual will put even more effort into ensuring that they benefit from personal development opportunities in terms of meaningfulness, which, in turn, will result in repayment in terms of increased engagement. Based on these propositions, line managers are in a position to strengthen employees' ability to transform the perceived value and worth of development opportunities into the experience of meaningfulness. It is proposed that the positive relationship between perceived opportunities for development and meaningfulness will be stronger for employees who perceive that they have a high quality relationship line manager than for those who do not hold such perceptions.

Hypothesis 2: Perceived line manager relations will moderate the relationship between perceived opportunities for development and meaningfulness.

In sum, this study predicts that perceived opportunities for development leads to job engagement indirectly via the experience of meaningfulness (Hypothesis 1), and that this relationship is conditional upon the degree to which the employee perceives that they have a high quality relationship with their line manager (Hypothesis 2). This model is illustrated in Figure 1.

\section{INSERT FIGURE 1 ABOUT HERE}

\section{Method}

\section{Participants and procedure}

The study was designed as two online questionnaires: the first assessed perceived opportunities for development, perceptions of line manager relations, and meaningfulness (i.e., predictor, mediator, and moderator); and the second was conducted one month later and assessed the dependent variable, namely job engagement. A time lagged design was used in order to minimize common method bias. Separating out the measurement of independent and 
dependent variables in time reduces respondent biases in retrieving and recalling information and contextual cues (Podsakoff, MacKenzie, Lee, \& Podsakoff, 2003). Similarly to Karatepe and Ngeche (2012) and Paek, Schuckert, Kim, and Lee (2015), a one month interval was used because it reduces memory decay, prevents masking a relationship that really exists, and enables the effects of affective states, such as meaningfulness, to be captured reasonably well. Three thousand UK workers were asked to participate in the study via a market research company. The sample was generated by the market research company from a database of enrolled members of the public who receive credit points for completing surveys sent by the company. These points can be exchanged for monetary vouchers once enough have been gained. A total of 302 (response rate of $10 \%$ ) completed the first online questionnaire; of these, 152 (around half) also went on to complete the second online questionnaire one month later. It should be noted that the 152 individuals included in this study represents a very low overall response rate from those initially invited (5\%) - this was partly due to the researcher's small available budget that only allowed a total of just over 300 to be completed initially, and partly due to a tight response timeframe of one week being imposed on the second questionnaire. Of the 152 that fully completed both questionnaires, half were male, two thirds did not have managerial responsibility, and the same proportion were full-time. They represented a range of occupational and industrial sectors with the most from professional/associated professional (27\%), administration/ secretarial (23\%), and skilled trades/manual (17\%).

\section{Measures}

All measures used a 7-pt Likert scale (1-strongly disagree to 7-strongly agree). 
Four items were developed by the author to assess perceived opportunities for development, an example item being 'I have many opportunities to develop my personal skills and abilities'. These items were designed to capture the individual's perceptions regarding the formal (e.g., secondments, qualifications) and informal (e.g., increased responsibilities, leading on a new project) opportunities available to them to develop their personal skills/abilities as well as their careers (Shuck \& Rocco, 2014). The items drew upon those from Lee and Bruvold's (2003) and Kuvaas and Dysvik's (2010) perceived investment in employee development scales, as well as Bakker and Bal's (2010) opportunity for development scale. The remaining items can be found in Table 1 . The inter-item reliability of this scale was $\alpha=.90$.

\section{Perceived line manager relations}

Four items were developed by the author to assess perceived line manager relations, an example item being 'My immediate manager motivates me to perform well'. These items drew upon Rhoades, Eisenberger, \& Armeli's (2001) perceived supervisory support scale and Graen and Uhl-Bien's (1995) leader-member exchange scale. The remaining items can be found in Table 1 . The inter-item reliability of this scale was $\alpha=.85$.

As the scales for perceived opportunities for development and perceived line manager relations were constructed by the author, a principal components analysis was conducted using oblimin rotation to ensure that these two factors were distinct. Table 1 shows that two factors were extracted and that these reflected the items for each scale, respectively. To further test the validity of these scales, additional data was collected to compare the psychometric properties of the scales to alternative published scales. Additional tests confirmed that the scales developed in this paper were psychometrically comparable to other similar, published scales ${ }^{1}$.

\footnotetext{
${ }^{1}$ The results from these additional analyses are available from the author upon request
} 


\section{Meaningfulness}

May et al's (2004) six item meaningfulness scale was used to assess an individual's perceived sense that their work is personally worthwhile and valuable (Kahn, 1990). An example item is 'The work I do on this job is very important to me'. Its inter-item reliability was $\alpha=.95$.

\section{Job engagement}

Job engagement was measured one month after the first questionnaire using a 9-item shortened version of Rich, Lepine, and Crawford's (2010) 18-item job engagement scale. This scale represents the emotional, cognitive and behavioral components of engagement as conceptualized within HRM research (e.g., Alfes et al., 2013; Shuck et al., 2014). Three items assessed each dimension of engagement: emotional, an example item being 'I am enthusiastic about my job'; cognitive, an example item being 'At work, my mind is focused on my job', and physical, an example item being 'I exert my full effort to my job'. Participants were instructed to focus on how they have felt about their job over the past month. Inter-item reliabilities for the dimensions ranged from $\alpha=.92$ to .97 , and for job engagement as a whole was found to be $\alpha=.96$. The dimensions were strongly correlated with each other ( $\mathrm{r}=.61$ to .87), thus supporting engagement as a higher-order construct. To further verify the factor structure, Harman's one factor test was conducted. The one factor structure was a poor fit: $\chi^{2}$ $(27)=505.07, p<.001 ; \chi^{2} / \mathrm{df}=18.70 ; \mathrm{RMSEA}=.34, \mathrm{CFI}=.73, \mathrm{TLI}=.71, \mathrm{SRMR}=.10$, whereas the hypothesized three factor structure was an acceptable fit: $\chi^{2}(24)=74.40, p<$ $.001 ; \chi^{2} / \mathrm{df}=3.10 ; \mathrm{RMSEA}=.10, \mathrm{CFI}=.97, \mathrm{TLI}=.95, \mathrm{SRMR}=.04$, and a better fit than the one factor alternative: $\Delta \chi^{2}(3)=430.67, p<.001$.

\section{Control variables}

Similarly to other engagement studies (e.g. Alfes et al., 2013; Kuvass \& Dysvik, 2010; Kuvass et al., 2012), gender ( 0 - male, 1 - female), age (in years), fulltime ( 0 - no, 1 - yes), 
management responsibility ( 0 - no, 1 - yes), and job tenure (in years) were controlled for in analyses as these may influence engagement and/or other independent variables in the study.

INSERT TABLE 1 ABOUT HERE

\section{Results}

\section{Descriptive statistics}

Means, standard deviations, reliability alphas, and correlations between the variables are given in Table 2.

\section{INSERT TABLE 2 ABOUT HERE}

\section{Measurement models}

Although the dependent variable was measured at a later time point than the independent variables, all of the measures were self-report. Therefore there is a need to examine the discriminant validity of the constructs (Podsakoff et al., 2003), and so confirmatory factor analyses (CFAs) were conducted to verify the factor structure of the hypothesized model. The likelihood ratio $\chi^{2}$ and degrees of freedom were calculated. The following fit indices were also used to determine model fit more accurately: a) $\chi^{2} / \mathrm{df}$ ratio where values of below three indicate good fit; b) Root Mean Square Error of Approximation (RMSEA) where values of .10 or below indicates a plausible fit; c) the Comparative Fit Index and Tucker Lewis Index (CFI/TFI), where values of .90 or above indicates a plausible fit; d) the standardized Root Mean Square Residual (SRMR) where values of .08 or below indicates a plausible fit. A model can be confirmed as an acceptable fit when the majority of these are within the reported boundaries; relying on them individually can be problematic due to sample size issues and other statistical confounds (Hair et al., 2005).

All of the constructs were represented by their constituent items, except job engagement which was represented by its sub-dimensions (i.e., emotional, cognitive, and 
physical). This is because, as highlighted in the measures section, job engagement is operationalized as a second-order factor. Representing a higher-order factor in this way is acceptable within CFA analyses (Martin, Malmberg, \& Liem, 2010). The results of the CFAs (see Table 3) shows that the hypothesized four factor structure was an acceptable fit; although the RMSEA and SRMR are on the boundaries of acceptability: $\chi^{2}(113)=282.50, p<.001$; $\chi^{2} / \mathrm{df}=2.50, \mathrm{RMSEA}=.10, \mathrm{CFI}=.94, \mathrm{TLI}=.92, \mathrm{SRMR}=.08$; and was a better fit than the alternative factor models, thus adding weight to the acceptability of the hypothesized model.

\section{INSERT TABLE 3 ABOUT HERE}

\section{Tests of hypotheses}

Hierarchical multiple regressions were used to test Hypothesis 1, and hierarchical moderated regression was used to test Hypothesis 2. All continuous independent variables were standardized to reduce the likelihood of multicollinearity; the dependent variable in any analysis remained unstandardized (Aiken \& West, 1991). In order to test for mediation the following steps were tested as outlined by Baron and Kenny (1986). First, the predictor (i.e., perceived opportunities for development) should be significantly related to the dependent variable (i.e., job engagement). Second, the mediator (i.e., meaningfulness) should be significantly associated with the dependent variable. Third, the predictor and the mediator should be correlated with each other. Lastly, when the mediator is included in the model with the predictor, it should reduce the association between the predictor and the dependent variable, and its relationship with the dependent variable should be strong.

Table 4 shows the results of these steps. The first step found that perceived opportunities for development was positively related with job engagement $(\beta=.25, p<.01)$, thereby meeting the first condition for mediation. The second step found that meaningfulness was positively associated with job engagement $(\beta=.54, p<.001)$, thus meeting the second condition for mediation. Table 4 also shows that perceived opportunities for development 
was positively related with meaningfulness $(\beta=.38, p<.001)$, and so the third condition of mediation is met. The final (fourth) step included both perceived opportunities for development and meaningfulness in the prediction of job engagement. This resulted in a reduction of the relationship between perceived opportunities for development and job engagement to non-significance $(\beta=.05, p>.05)$, yet the positive association between meaningfulness and job engagement remained strong $(\beta=.52, p<.001)$. Therefore the fourth condition of mediation is met, and the results suggest that meaningfulness fully mediates the relationship between perceived opportunities for development and job engagement. Sobel's test (1982) for indirect effects verifies this finding $(z=4.00, p<.001)$, and so the first hypothesis was supported.

\section{INSERT TABLE 4 ABOUT HERE}

The second hypothesis predicted that the relationship between perceived opportunities for development and meaningfulness would be moderated by perceived line manager relations. As this would also affect the indirect relationship between perceived opportunities for development and job engagement via meaningfulness (see Figure 1), it is known as a moderated mediation model. Moderated mediation analyses are used to clarify the boundary conditions of the mechanisms by which a predictor influences an outcome through a mediating process (Preacher, Rucker, \& Hayes, 2007; Hayes, 2015). It is particularly useful when a mediational process has been evidenced, yet there remains questions regarding when and in what circumstances this occurs, for example does the mediating process differ for men versus women, or between highly demanding versus highly predictable work environments (Muller et al., 2005). In this case, there are questions remaining as to whether the relationship with one's line manager influences how perceived opportunities for development leads to engagement through the psychological experience of meaningfulness. 
To assess moderated mediation, the recommendations outlined by Preacher et al. (2007) and Hayes (2014) were followed. First, the predictor as well as the mediator must be significantly associated with the dependent variable. Table 4 confirms that perceived opportunities for development as well as meaningfulness positively predicts levels of job engagement one month later. Second, the interaction of the predictor and moderator should significantly influence the mediator, and explain additional variance in the mediator than when the predictor and moderator are considered as independent variables. The results of this analysis, shown in Table 5, find that perceived line manager relations interacted with perceived opportunities for development to predict meaningfulness $(\beta=.22, p<.01)$ and explained 5\% of additional variance, thus meeting the second main condition of moderated mediation. Third, the magnitude of the conditional indirect effect of the predictor (i.e., perceived opportunities for development) on the dependent variable (i.e., job engagement) through the mediator (i.e., meaningfulness) should be different at high versus low levels (i.e., 1 standard deviation above versus 1 standard deviation below) of the moderator (i.e., perceived line manager relations). The conditional indirect effects were calculated using Hayes (2014) PROCESS macro for SPSS, which uses regression-based approaches and bootstrapping techniques. Table 6 shows the results of these calculations and confirms that the indirect effect is different at high versus low levels of the moderator, thus meeting the forth condition of moderated mediation. Moreover, the moderated mediation index (a quantified value of the strength of association between the indirect effect and the moderator) is significant: Index $=.13$; bootstrapped confidence interval $=.04$ to .27 (Hayes, 2015). Further examination of Table 6 reveals that the indirect effect is significant only at high levels of perceived line manager relations. When perceived line manager relations are low then perceived opportunities for development will not translate into higher levels of meaningfulness, which consequently will not lead to greater engagement. Figure 2 plots this 
interaction, and shows that perceived line manager relations strengthens the relationship between perceived opportunities for development and meaningfulness. Collectively these analyses give strong support for the second hypothesis.

\section{INSERT TABLE 5 ABOUT HERE}

INSERT TABLE 6 ABOUT HERE

\section{INSERT FIGURE 2 ABOUT HERE}

\section{Discussion}

The present paper sought to address a gap within HRM research on engagement; namely the psychological processes that underpin the relationship between personal development and engagement. Understanding such processes are important for understanding how development practices can be best designed and implemented to facilitate engagement. It was firstly hypothesized that the positive relationship between perceived opportunities for development and engagement would be mediated by meaningfulness. Furthermore, it was predicted that this mediated relationship would be conditional upon the quality of the employee-line manager relationship. The study's findings support these hypotheses, and in doing so makes three substantial contributions to the HRM literature on engagement.

First, the findings that perceived opportunities for development and meaningfulness positively predict levels of job engagement one month later support prior studies that have demonstrated these direct relationships (e.g. Chen et al., 2011; Shuck et al., 2014). Thus, the study corroborates the assertion that opportunities for personal and career development are motivational job resources, as theorized by the J D-R model (Crawford et al., 2014), which signify that the organization values and cares about its employees (Lee \& Bruvold, 2003). Moreover, it suggests that meaningfulness triggers a resource investment process in which 
the individual invests themselves, i.e. engages, in their work role to protect and enhance their wellbeing (Hobfoll, 1989; 2011).

Second, the study showed the relationship between perceived opportunities for development and job engagement was fully mediated by meaningfulness. This indicates that broaden-and-build theory (Fredrickson, 2001) may explain the intermediary psychological process that links personal development with engagement, and indicates that HRM and engagement scholars should examine this theory in more depth. Within the context of engagement, Shuck and Rose (2013) suggest that meaningfulness can be interpreted as contribution, influence, and reward; and Kahn and Heaphy (2014) highlight the relational dimensions of deepened purpose and heightened belongingness as important pathways through which meaningfulness and engagement are shaped. Thus, these avenues through which meaningfulness can manifest and influence engagement warrant further investigation, and broaden-and-build theory (Fredrickson, 2001) may provide a unified, explanatory framework for examining these pathways.

Finally, it was revealed that an employee's perceived relationship with their line manager was particularly important for the positive effects of personal development to occur. The study found that the employee's perceived quality of the relationship between themselves and their line manager moderated the relationship between perceived opportunities for development and meaningfulness. The positive indirect relationship between perceived opportunities and engagement via meaningfulness was significant for those who held moderate or strong perceptions that their relationship with their manager was positive and motivational. For those who viewed their relationship with their manager as poor, perceived opportunities for development did not translate into meaningfulness, and consequently did not foster engagement. This supports and extends previous studies that show how supportive and motivational line managers enable the positive effects of job and organizational 
resources, such as job clarity and employee development, to occur (Kuvaas \& Dysvik, 2010; Mendes \& Stander, 2011). It highlights how social exchange theory (Blau, 1964) may not necessarily explain the psychological process through which personal development translates into engagement, but rather how it may identify the boundary conditions that those psychological processes operate in (cf Kuvass et al., 2012; Shuck et al., 2014). For instance, the findings suggest that the relationship with the line manager affects the extent to which personal development enhances a sense of meaningfulness and subsequently elicits engagement, such that when the relationship is weak or poor then the potential positive effects of personal development may not be realized. This underscores the critical importance of the quality of the line manager-employee relationship to the functioning of motivational processes. Overall, the present study suggests that engagement theory could be advanced by integrating broaden-and-build (Fredrickson, 2001) and social exchange (Blau, 1964) explanations. This may provide a more sophisticated understanding of how HR practices can be designed and implemented to foster and maintain high levels of employee engagement.

\section{Practical implications}

This study provides HRM practitioners with further evidence to demonstrate the positive benefits that personal and career development have on individual employees. In particular, it suggests that organizations wishing to foster high levels of employee engagement may want to consider providing more opportunities for personal development. These may include establishing clear routes for career advancement and progression, arranging secondments and cross-departmental workgroups, or utilizing personal development plans within the appraisal process (Shuck \& Rocco, 2014). However, it should be noted that this study underscores the importance of employee perceptions of these practices, and perceptions may not completely reflect the reality of provision so organizations should be cognisant of perceptual and attributional biases when evaluating the effectiveness of their development initiatives (Nishii, 
Lepak, \& Schneider, 2008). Furthermore, organizations should reflect on how meaningfulness can be promoted within the organization, and how development practices and organizational systems can create meaning and purpose. For example, making explicit connections between an individual's personal development goals and wider values, goals and mission of the organization (Shuck \& Rose, 2013); providing developmental opportunities that enable the individual to have contact with, and see the impact of their work, on beneficiaries (Grant, 2007); or promoting developmental goals and opportunities that seek to affirm one's social/professional identities (Kahn \& Heaphy, 2014), such as being sponsored by the organisation to undertake a professional accreditation qualification. However, this study highlights how providing development opportunities and creating meaning is not in itself going to lead to meaningfulness nor to engagement. Line managers are integral to transforming these opportunities into meaningful and engaging experiences. Employees who feel that they do not have a high quality relationship with their line manager may not receive the benefit of personal development activities. Thus, organizations must ensure that line managers are selected, trained and regularly monitored so that they enact motivational leadership, social support, and coaching behaviors (Kahn \& Heaphy, 2014).

\section{Limitations and conclusion}

The findings of this study should be interpreted with the following limitations in mind. First, all variables were assessed using self-report Likert scales and so common method bias may have been an issue (Podsakoff et al., 2003). However, the results of the CFAs conducted (see Table 3) did not show that this was of major concern in the current study. Related to this, the scales used to measure perceived opportunities for development and perceived line manager relations were designed specifically for the study. Although reliability and validity tests were conducted and an additional study confirmed that these scales were comparable with other published scales, it may be worthwhile to further validate these constructs. 
Although the time lag of one month between the predictors and job engagement was chosen due to the state-like nature of meaningfulness and engagement (Kahn, 1990), there is no agreed length of time for measuring changes in these states. Engagement research has used various units of analysis, and have found that engagement, and some of its antecedents, vary considerably across days (e.g., Xanthopoulou, Bakker, Demerouti, \& Schaufeli, 2009b), weeks (e.g., Bakker \& Bal, 2010), months (e.g., Halbesleben \& Wheeler, 2008) and years (e.g., Yalabik, Popaitoon, Chowne, \& Rayton, 2013). As a one month time lag was used, this current study chose to direct attention of the respondent to how they felt during the last month in order to reduce the potential for variation regarding the implicit timeframe each individual may have used to judge their engagement levels, and in doing so would better enable the distinct (temporal) separation between the evaluation of independent variables and the dependent variable. Future research that clarifies the precise temporal dynamics of engagement, and how to measure engagement over different timeframes, would be welcome.

The study focused specifically on opportunities for development and the moderating role of line managers. Future research that investigates the moderation effects of line managers on a wider range of HR practices will provide further insight into the role of line managers have on how HR practices are interpreted, experienced, and perceived by employees, and how these then shape future expectations as recent work by Piening, Baluch and Ridder (2013) show that employee expectations may have a strong influence on their experience of HR practices. Moreover, examining how other social exchange constructs, such as norms of reciprocity (Wu et al., 2006), interact with affective processes will shed light on how social exchange and broaden-and-build processes combine to influence engagement.

A market research organization was used to maximize the sample range and generalizability of findings; a practice of data collection that is becoming more widely used across a range of management disciplines to obtain a wide sample pool, particularly when 
budgets and resources are limited (Shoenherr, Ellram, \& Tate, 2015). However, there are issues with collecting data in this way, particularly the issue of being rewarded for participating, which may bias the types of people that complete the survey and may limit sample verification and transparency (Schoenherr et al., 2015). Further research that collects data from specific organizational settings would therefore be beneficial.

To conclude, this study was one of the first to examine how personal development may lead to increased engagement through the experience of meaningfulness. In doing so, it provides two novel findings that contribute to the engagement literature. First, it was found that meaningfulness positively mediated the relationship between perceived opportunities for development and job engagement. Thus, it empirically demonstrated that personal development facilitates engagement through the experience of meaningfulness, and suggests that broaden-and-build theory can explain the psychological processes that underpin engagement. Second, the study showed that the positive effects of perceived opportunities for development were conditional on the level of line manager relations, such that such effects were not significant for those who perceived the relationship with their line manager as weak. This highlights the importance of the line management relationship in enabling the positive effects of personal development to be realized. Moreover, it suggests that engagement and HRM scholars should consider how perceptions of HR practices may interact with social exchange mechanisms, such as trust and reciprocity, to influence the experience of these important psychological states.

\section{References}

Aiken, L.S., \& West, S.G. (1991). Multiple Regression: Testing and Interpreting Interactions. Newbury Park, CA: Sage.

Alfes, K., Shantz, A., Truss, C., \& Soane, E.C. (2013). The link between perceived human resource management practices, engagement and employee behavior: A moderated 
mediation model. The International Journal of Human Resource Management, 24, 330-351. doi:10.1080/09585192.2012.679950

Arrowsmith, J., \& Parker, J. (2013). The meaning of 'employee engagement' for the values and roles of the HRM function. The International Journal of Human Resource Management, 24, 2692-2712. doi: 10.1080/09585192.2013.763842

Bailey, C., Madden, A., Alfes, K., \& Fletcher, L. (2015). The meaning, antecedents and outcomes of employee engagement: A narrative evidence synthesis. International Journal of Management Reviews, online first. doi: 10.1111/ijmr.12077

Bakker, A. B., \& Bal, P. M. (2010). Weekly work engagement and performance: A study among starting teachers. Journal of Occupational and Organizational Psychology, 83, 189-206. doi: 10.1348/096317909X402596

Bakker, A. B., \& Demerouti, E. (2008). Towards a model of work engagement. Career Development International, 13, 209-223. doi:10.1108/13620430810870476

Bal, P. M., Kooij, D. T., \& De Jong, S. B. (2013). How do developmental and accommodative HRM enhance employee engagement and commitment? The role of psychological contract and SOC strategies. Journal of Management Studies, 50, 545-572. doi: 10.1111/joms.12028

Baron, R. M., \& Kenny, D. A. (1986). The moderator-mediator variable distinction in social psychological research: Conceptual, strategic and statistical considerations. Journal of Personality and Social Psychology, 51, 1173-1182. doi:10.1037/0022 3514.51.6.1173

Barrick, M. R., Mount, M. K., \& Li, N. (2013). The theory of purposeful work behavior: the role of personality, higher-order goals, and job characteristics. Academy of Management Review, 38, 132-153. doi: 10.5465/amr.2010.0479

Blau, P. M. (1964). Exchange and Power in Social Life. New York, NY: Wiley. 
Chen, Z., Zhang, X., \& Vogel, D. (2011). Exploring the underlying process between conflict and knowledge sharing: A work-engagement perspective. Journal of Applied Social Psychology, 41, 1005-1033. doi:10.1111/j.1559-1816.2011.00745.

Crawford, E.R., Rich, B.L., Buckman, B., \& Bergeron, J. (2014). The antecedents and drivers of employee engagement. In C. Truss et al (Eds.), Employee Engagement in Theory and Practice (pp. 57-81). London: Routledge.

Crawshaw, J.R. \& Game, A. (2015). The role of line managers in employee career management: an attachment theory perspective. The International Journal of Human Resource Management, 26, 1182-1203. doi: 10.1080/09585192.2014.934886

Fletcher, L. (2016). Training perceptions, engagement and performance: Comparing personal role engagement and work engagement. Human Resource Development International, 19, 4-26. doi: 10.1080/13678868.2015.1067855

Fredrickson, B. L. (2001). The role of positive emotions in positive psychology: The broaden-and-build theory of positive emotions. American Psychologist, 56, 218-226. doi:10.1037/0003-066X.56.3.218

Graen, G. B., \& Uhl-Bien, M. (1995). Relationship-based approach to leadership: Development of leader-member exchange (LMX) theory of leadership over 25 years: Applying a multi-level multi-domain perspective. The Leadership Quarterly, 6, 219247. doi: 10.1016/1048-9843(95)90036-5

Grant, A. M. (2007). Relational job design and the motivation to make a prosocial difference. Academy of Management Review, 32, 393-417. doi: 10.5465/AMR.2007.24351328

Hair, J. F., Black, W. C., Babin, B. J., Anderson, R. E., \& Tatham, R. L. (2005). Multivariate Data Analysis (6 ${ }^{\text {th }}$ ed.). Upper Saddle River, NJ: Pearson Prentice Hall. 
Halbesleben, J. R., \& Wheeler, A. R. (2008). The relative roles of engagement and embeddedness in predicting job performance and intention to leave. Work \& Stress, 22, 242-256. doi: 10.1080/02678370802383962

Hayes, A.F. (2014). The PROCESS macro for SPSS and SAS. Version 2.13. [Computer Software]. Available from www.processmacro.org

Hayes, A.F. (2015). An index and test of linear moderated mediation. Multivariate Behavioral Research, 50, 1-22. doi: 10.1080/00273171.2014.962683

Hobfoll, S. E. (1989). Conservation of resources: A new attempt at conceptualizing stress. American Psychologist, 44, 513-524. doi:10.1037/0003-066X.44.3.513

Hobfoll, S. E. (2011). Conservation of resource caravans and engaged settings. Journal of Occupational and Organizational Psychology, 84, 116-22. doi:10.1111/j.2044 8325.2010.02016.x

Kahn, W. A. (1990). Psychological conditions of personal engagement and disengagement at work. Academy of Management Journal, 33, 692-724. doi:10.2307/256287

Kahn, W. A. (2010). The essence of engagement: lessons from the field. In S.L. Albrecht (Ed.), Handbook of Employee Engagement: Perspectives, Issues, Research and Practice (pp.20-30). Cheltenham: Edward Elgar.

Kahn, W.A., \& Heaphy, E.D. (2014). Relational contexts of personal engagement at work. In C. Truss et al (Eds.), Employee Engagement in Theory and Practice (pp.82-96). London, UK: Routledge.

Koster, F., de Grip, A., \& Fouarge, D. (2011). Does perceived support in employee development affect personnel turnover?. The International Journal of Human Resource Management, 22, 2403-2418. doi:10.1080/09585192.2011.584404

Kuvaas, B., \& Dysvik, A. (2010). Exploring alternative relationships between perceived investment in employee development, perceived supervisor support and employee 
outcomes. Human Resource Management Journal, 20, 138-156. doi: 10.1111/j.1748-8583.2009.00120.x

Kuvaas, B., Buch, R., \& Dysvik, A. (2012). Perceived training intensity and knowledge sharing: Sharing for intrinsic and prosocial reasons. Human Resource Management, 51, 167-187. doi: 10.1002/hrm.21464

Lee, C.H., \& Bruvold, N.T. (2003). Creating value for employees: Investment in employee development. The International Journal of Human Resource Management, 14, 9861000. doi:10.1080/0958519032000106173

Martin, A.J., Malmberg, L.E., \& Liem, G.A.D. (2010). Multilevel motivation and engagement: Assessing construct validity across students and schools. Educational and Psychological Measurement, 70, 973-989. doi:10.1177/0013164410378089

May, D.R., Gilson, R.L., \& Harter, L.M. (2004). The psychological conditions of meaningfulness, safety and availability and the engagement of the human spirit at work. Journal of Occupational and Organizational Psychology, 77, 11-37. doi:10.1348/096317904322915892

Mendes, F., \& Stander, M. W. (2011). Positive organisation: The role of leader behaviour in work engagement and retention. SA Journal of Industrial Psychology, 37, 1-13. Accessed from http://www.sajip.co.za

Muller, D., Judd, C. M., \& Yzerbyt, V. Y. (2005). When moderation is mediated and mediation is moderated. Journal of Personality and Social Psychology, 89, 852-863. doi: $10.1037 / 0022-3514.89 .6 .852$

Nishii, L. H., Lepak, D. P., \& Schneider, B. (2008). Employee attributions of the "why" of HR practices: Their effects on employee attitudes and behaviors, and customer satisfaction. Personnel Psychology, 61, 503-545. doi: 10.1111/j.1744 6570.2008.00121.x 
Paek, S., Schuckert, M., Kim, T. T., \& Lee, G. (2015). Why is hospitality employees' psychological capital important? The effects of psychological capital on work engagement and employee morale. International Journal of Hospitality Management, 50, 9-26. doi: 10.1016/j.ijhm.2015.07.001

Piening, E. P., Baluch, A. M., \& Ridder, H. G. (2014). Mind the intended-implemented gap: Understanding employees' perceptions of HRM. Human Resource Management, 53, 545-567. doi: 10.1002/hrm.21605

Podsakoff, P. M., MacKenzie, S. B., Lee, J. Y., \& Podsakoff, N. P. (2003). Common method biases in behavioral research: A critical review of the literature and recommended remedies. Journal of Applied Psychology, 88, 879-903. doi:10.1037/0021-9010.88.5.879

Preacher, K. J., Rucker, D. D., \& Hayes, A. F. (2007). Addressing moderated mediation hypotheses: Theory, methods, and prescriptions. Multivariate Behavioral Research, 42, 185-227. doi: 10.1080/00273170701341316

Purcell, J., \& Hutchinson, S. (2007). Front-line managers as agents in the HRM-performance causal chain: theory, analysis and evidence. Human Resource Management Journal, 17, 3-20. doi: 10.1111/j.1748-8583.2007.00022.x

Reissner, S., \& Pagan, V. (2013). Generating employee engagement in a public-private partnership: management communication activities and employee experiences. The International Journal of Human Resource Management, 24, 2741-2759. doi: $10.1080 / 09585192.2013 .765497$

Rhoades, L., Eisenberger, R., \& Armeli, S. (2001). Affective commitment to the organization: The contribution of perceived organizational support. Journal of Applied Psychology, 86, 825-836. doi: 10.1037/0021-9010.86.5.825 
Rich, B. L., Lepine, J. A., \& Crawford, E. R. (2010). Job engagement: Antecedents and effects on job performance. Academy of Management Journal, 53, 617-635. doi: 10.5465/AMJ.2010.51468988

Rosso, B. D., Dekas, K. H., \& Wrzesniewski, A. (2010). On the meaning of work: A theoretical integration and review. Research in Organizational Behavior, 30, 91-127. doi:10.1016/j.riob.2010.09.001

Saks, A.M. \& Gruman, J.A. (2014). What do we really know about employee engagement?. Human Resource Development Quarterly, 25, 155-182. doi: 10.1002/hrdq.21187

Sarti, D. (2014). Job resources as antecedents of engagement at work: evidence from a long term care setting. Human Resource Development Quarterly, 25, 213-237. doi:10.1002/hrdq.21189.

Schoenherr, T., Ellram, L.M., \& Tate, W.L. (2015). A note on the use of survey research firms to enable empirical data collection. Journal of Business Logistics, 36, 288-300. doi: $10.1111 /$ jbl.12092

Shuck, B. \& Rocco, T.S. (2014). Human resource development and employee engagement. In C. Truss et al (Eds.), Employee Engagement in Theory and Practice (pp. 116-130). London: Routledge. ISBN: 978-0415657426

Shuck, B., \& Rose, K. (2013). Reframing employee engagement within the context of meaning and purpose: Implications for HRD. Advances in Developing Human Resources, 15, 341-355. doi: 10.1177/1523422313503235

Shuck, B., Twyford, D., Reio, T.G. \& Shuck, A. (2014). Human resource development practices and employee engagement: Examining the connection with employee turnover intentions. Human Resource Development Quarterly, 25, 239-270. doi: 10.1002/ hrdq. 21190 
Soane, E., Shantz, A., Alfes, K., Truss, C., Rees, C., \& Gatenby, M. (2013). The association of meaningfulness, well-being, and engagement with absenteeism: A moderated mediation model. Human Resource Management, 52, 441-456. doi:10.1002/hrm.21534

Sobel, M. E. (1982). Asymptotic confidence intervals for indirect effects in structural equation models. Sociological Methodology, 13, 290-312. Accessed from http://www.jstor.org/stable/270723

Wayne, S. J., Shore, L. M., \& Liden, R. C. (1997). Perceived organizational support and leader-member exchange: a social exchange perspective. Academy of Management Journal, 40, 82-111. doi: 10.2307/257021

Wang, H., Law, K. S., Hackett, R. D., Wang, D., \& Chen, Z. X. (2005). Leader-member exchange as a mediator of the relationship between transformational leadership and followers' performance and organizational citizenship behavior. Academy of Management Journal, 48, 420-432. doi: 10.5465/AMJ.2005.17407908

Wright, P. M., \& Nishii, L. H. (2007). Strategic HRM and Organizational Behavior: Integrating Multiple Levels of Analysis (CAHRS Working Paper \#07-03). Ithaca, NY: Cornell University. http://digitalcommons.ilr.cornell.edu/cahrswp/468

Wu, J. B., Hom, P. W., Tetrick, L. E., Shore, L. M., Jia, L., Li, C., \& Song, L. J. (2006). The norm of reciprocity: Scale development and validation in the Chinese context. Management and Organization Review, 2, 377-402.doi: 10.1111/j.1740 8784.2006.00047.x

Xanthopoulou, D., Bakker, A. B., Demerouti, E., \& Schaufeli, W. B. (2009a). Reciprocal relationships between job resources, personal resources, and work engagement. Journal of Vocational Behavior, 74, 235-244. doi: 10.1016/j.jvb.2008.11.003 
Xanthopoulou, D., Bakker, A.B., Demerouti, E., \& Schaufeli, W.B. (2009b). Work

engagement and financial returns: A diary study on the role of job and personal

resources. Journal of Occupational and Organizational Psychology, 82, 183-200. doi: $10.1348 / 096317908 \times 285633$

Yalabik, Z. Y., Popaitoon, P., Chowne, J. A., \& Rayton, B. A. (2013). Work engagement as a mediator between employee attitudes and outcomes. The International Journal of Human Resource Management, 24, 2799-2823. doi: 10.1080/09585192.2013. 763844

Zhu, W., Avolio, B. J., \& Walumbwa, F. O. (2009). Moderating role of follower characteristics with transformational leadership and follower work engagement. Group \& Organization Management, 34, 590-619. doi: 10.1177/1059601108331242

Table 1. Principal components analysis of the perceived opportunities for development and perceived line manager relations items.

\begin{tabular}{|lll|}
\hline & $\begin{array}{l}\text { Factor 1: } \\
\text { Perceived } \\
\text { opportunities for } \\
\text { development }\end{array}$ & $\begin{array}{l}\text { Factor 2: } \\
\text { Perceived line } \\
\text { manager } \\
\text { relations }\end{array}$ \\
\hline $\begin{array}{l}\text { Item statement } \\
\text { and learning }\end{array}$ & $\mathbf{. 9}$ & .23 \\
$\begin{array}{l}\text { I have opportunities to advance my career here, e.g. } \\
\begin{array}{l}\text { Promotions, increased responsibilities } \\
\text { This organization provides me with a variety of development } \\
\text { opportunities, e.g. Projects, qualifications, CPD, secondments }\end{array}\end{array}$ & $\mathbf{. 8 8}$ & -.06 \\
$\begin{array}{l}\text { I have many opportunities to develop my personal skills and } \\
\text { abilities }\end{array}$ & $\mathbf{. 8 8}$ & -.09 \\
$\begin{array}{l}\text { My immediate manager motivates me to perform well } \\
\text { I have a good working relationship with my immediate } \\
\text { manager }\end{array}$ & .28 & .05 \\
$\begin{array}{l}\text { My immediate manager does not support me when things go } \\
\text { wrong (reverse scored) }\end{array}$ & .01 & $\mathbf{. 7 8}$ \\
$\begin{array}{l}\text { My immediate manager recognises my efforts when I have } \\
\text { performed well }\end{array}$ & -.17 & $\mathbf{. 9 1}$ \\
$\begin{array}{l}\text { Eigenvalue } \\
\text { \% of variance explained }\end{array}$ & .12 & $\mathbf{. 7 4}$ \\
\hline
\end{tabular}


Table 2. Means, standard deviations, correlations and reliability statistics of the study variables.

\begin{tabular}{|c|c|c|c|c|c|c|c|c|c|c|c|}
\hline Variable & Mean & SD & 1 & 2 & 3 & 4 & 5 & 6 & 7 & 8 & 9 \\
\hline 1. Gender & - & - & - & & & & & & & & \\
\hline 2. Age & 42.03 & 10.40 & -.11 & - & & & & & & & \\
\hline 3. Fulltime & - & - & $-21 * *$ & .02 & - & & & & & & \\
\hline $\begin{array}{l}\text { 4. Management } \\
\text { responsibility }\end{array}$ & - & - & -.08 & .07 & $.34 * * *$ & - & & & & & \\
\hline 5. Job tenure & & & -.12 & $.32 * * *$ & $.22 * *$ & $.16^{*}$ & - & & & & \\
\hline $\begin{array}{l}\text { 6. Perceived opportunities } \\
\text { for development }\end{array}$ & 4.09 & 1.32 & -.14 & -.04 & .06 & -.03 & .07 & $(.90)$ & & & \\
\hline $\begin{array}{l}\text { 7. Perceived line manager } \\
\text { relations }\end{array}$ & 4.67 & 1.42 & .01 & .07 & -.03 & -.05 & .09 & $.45^{* * *}$ & $(.85)$ & & \\
\hline 8. Meaningfulness & 5.15 & 1.30 & .02 & $.29 * * *$ & .04 & .03 & .08 & $.35^{* * *}$ & $.38 * * *$ & $(.95)$ & \\
\hline 9. Job engagement & 5.00 & 1.32 & -.03 & .12 & -.05 & -.13 & $\begin{array}{l}- \\
.04\end{array}$ & $.24 * *$ & $.18 *$ & $.52 * * *$ & $(.96)$ \\
\hline
\end{tabular}

Note: Values in parentheses are Cronbach alpha reliability scores. $* p<.05, * * p<.01, * * * p<.001$

Table 3. Fit statistics from measurement model comparison.

\begin{tabular}{|llllllllll|}
\hline Models & $\chi^{2}(\mathrm{df})$ & $\chi^{2} / \mathrm{df}$ & $\Delta \chi^{2}(\mathrm{df})$ & $\mathrm{AIC}$ & $\mathrm{BIC}$ & $\begin{array}{l}\text { RMSEA } \\
(95 \% \text { CI })\end{array}$ & CFI & TLI & SRMR \\
\hline $\begin{array}{l}1 \text { factor } \\
\text { alternative }\end{array}$ & $1208.65 * * *(119)$ & 10.16 & & 7911.54 & 8065.76 & $.25(.23-.26)$ & .59 & .53 & .19 \\
$\begin{array}{l}2 \text { factor } \\
\text { alternative }\end{array}$ & $825.37 * * *(118)$ & 6.99 & $383.28 * * *(1)$ & 7530.25 & 7687.50 & $.20(.19-.21)$ & .73 & .69 & .13 \\
$\begin{array}{l}3 \text { factor } \\
\text { alternative } \\
\mathbf{4} \text { factor full } \\
\text { hypothesized } \\
\text { model }\end{array}$ & $546.40 * * *(116)$ & 4.71 & $278.97 * * *(2)$ & 7255.29 & 7418.58 & $.16(.14-.17)$ & .84 & .81 & .12 \\
\end{tabular}

Note: 1 factor $=$ (perceived opportunities for development, perceived line manager relationship, meaningfulness, job engagement); 2 factor $=$ (perceived opportunities for development, perceived line manager relationship $) /($ meaningfulness, job engagement $) ; 3$ factor $=($ perceived opportunities for development, perceived line manager relationship) $/($ meaningfulness $) /($ job engagement $) ; 4$ factor $=$ (perceived opportunities for development)/(perceived line manager relationship)/(meaningfulness)/( job engagement). ${ }^{*} p<.05, * * p<.01$, $* * * p<.001$ 
Table 4. Hierarchical regression results for testing mediation.

\begin{tabular}{|c|c|c|c|c|c|c|}
\hline \multirow[b]{2}{*}{ Variables } & \multicolumn{4}{|c|}{ Predicting job engagement } & \multicolumn{2}{|c|}{ Predicting meaningfulness } \\
\hline & Control model & Step 1 & Step 2 & Step 3 & Control model & Step 1 \\
\hline Gender & -.02 & .01 & -.06 & -.05 & .06 & .11 \\
\hline Fulltime & .01 & -.00 & -.02 & -.02 & .06 & .05 \\
\hline Management responsibility & -.13 & -.12 & -.13 & -.13 & -.00 & .02 \\
\hline Meaningfulness & & & $.54 * * *$ & $.52 * * *$ & & \\
\hline F statistic & 1.17 & $2.61 *$ & $10.33 * * *$ & $8.89^{* * *}$ & $2.85^{*}$ & $7.18 * * *$ \\
\hline $\mathrm{R}^{2}\left(\right.$ Adj. $\left.\mathrm{R}^{2}\right)$ & $.04(.01)$ & $.10(.06)^{* *}$ & $.30(.27)^{* * * *}$ & $.30(.27)^{* * * *}$ & $.09(.06)$ & $.23(.20)^{* * *}$ \\
\hline
\end{tabular}

Table 5. Moderation of perceived line manager relations on perceived opportunities for development to meaningfulness.

\begin{tabular}{|lll|}
\hline & \multicolumn{2}{l|}{ Predicting meaningfulness } \\
\cline { 2 - 3 } Variables & Step 1 & Step 2 \\
\hline Gender & .09 & .10 \\
Age & $.31^{* * *}$ & $.30^{* * *}$ \\
Fulltime & .06 & .07 \\
Management responsibility & .02 & .01 \\
Job tenure & -.07 & -.07 \\
Perceived opportunities for development & $.27 * * *$ & $.28^{* * *}$ \\
Perceived line manager relations & $.25^{* *}$ & $.29 * * *$ \\
Perceived opportunities for development & & $.22^{* *}$ \\
x perceived line manager relations & & $8.64 * * *$ \\
F statistic & $7.96 * * *$ & $.33(.29)$ \\
$\mathrm{R}^{2}\left(\right.$ Adj. $\left.\mathrm{R}^{2}\right)$ & $.28(.24)$ & $.05^{* *}$ \\
$\Delta \mathrm{R}^{2}$ & & \\
$* p<.05, * * p<.01, * * * p<.001$ & &
\end{tabular}


Table 6. Moderated mediation results for the indirect effect of the perceived opportunities for development on job engagement, via meaningfulness, across levels of perceived line manager relations.

\begin{tabular}{|llllll|}
\hline Moderator & Level & $\begin{array}{l}\text { Conditional } \\
\text { indirect effect }\end{array}$ & SE & $\begin{array}{l}\text { Lower } \\
\text { Bound CI }\end{array}$ & $\begin{array}{l}\text { Upper } \\
\text { Bound CI }\end{array}$ \\
\hline $\begin{array}{l}\text { Perceived line } \\
\text { manager }\end{array}$ & High & .33 & .09 & .17 & .54 \\
relations & Low & .06 & .09 & -.12 & .24 \\
\hline
\end{tabular}

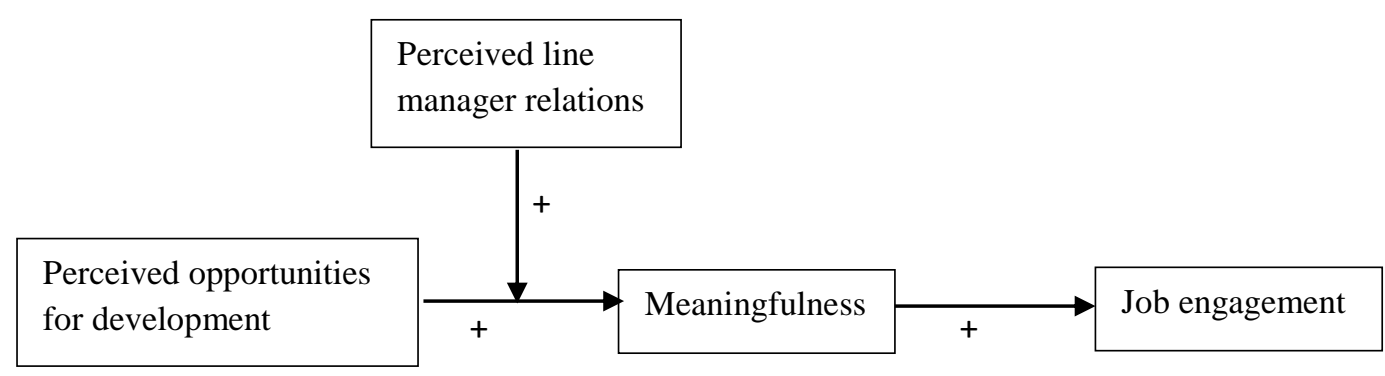

Figure 1. Hypothesized relationships between perceived opportunities for development, perceived line manager relations, meaningfulness, and job engagement.

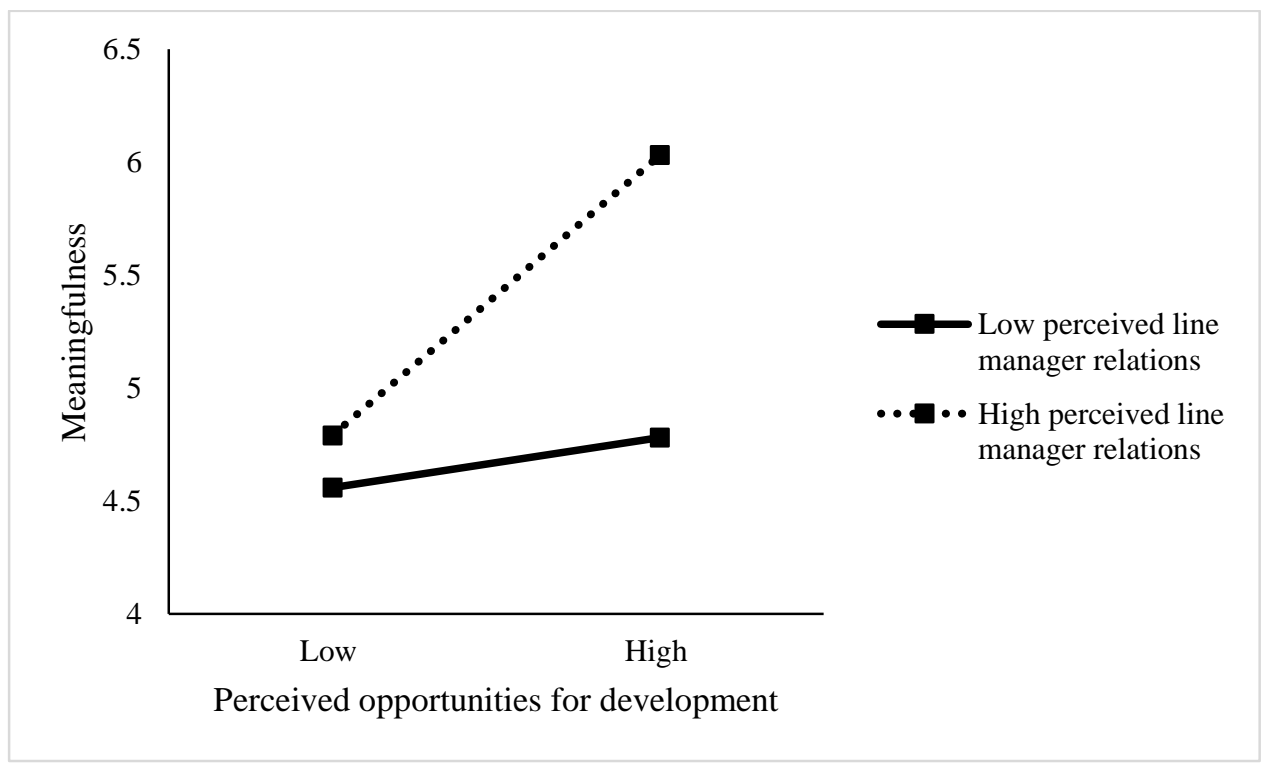

Figure 2. Perceived line manager relations strengthens the relationship between perceived opportunities for development and meaningfulness 